\title{
LIVE LINE MAINTENANCE OF TRANSMISSION LINES IN INDIAN PERSPECTIVE-A REVIEW.
}

\author{
H.A.Badgujar \\ Department of EE \\ R.C.Patel Polytechnic Shirpur, \\ Maharashtra India.
}

\begin{abstract}
In electrical engineering, live-line working, also known as hotline maintenance, is the maintenance of electrical equipment, often operating at high voltage, while the equipment is energized. Although this is more hazardous for personnel than working on electrical equipment with the power off, live-line maintenance techniques are used in the electric power distribution industry to avoid the disruption and high economic costs of having to turn off power to customers to perform essential periodic maintenance on transmission lines and other equipment. The first techniques for liveline working were developed in the early years of the 20th century, and both equipment and work methods were later refined to deal with increasingly higher voltages. In the 1960s, methods were developed in the laboratory to enable field workers to come into direct contact with high voltage lines. Such methods can be applied to enable safe work at the highest transmission voltages.
\end{abstract}

Keywords - Live, Maintenance, Transmission Line

\section{INTRODUCTION}

While the use of live-line maintenance tools is sometimes considered a recent development in the electrical power industry, forerunners of modern live-line tools made their appearance as far back as 1913. These initial tools were homemade, crude, and bulky; however, they sparked the development of our present efficient and refined tools.

In India Having a large amount of old aging transmission system life \& aging equipment results in higher probabilities of failure, higher maintenance cost \& higher replacement cost. Aging equipment will have to be replaced; this replacement should be planned in coordination with capacity additions [2]. Extra and ultra-high voltage transmission lines have been developed worldwide and are successfully being operated in developed nations. Recent trends in Indian transmission scenario are progressing towards establishing $765 \mathrm{KV}$ lines to strengthen its transmission infrastructure. Massive expansion of inter-state transmission system is under way to cater to the transmission requirement of new generation projects.
The maintenance of line conductors, line insulators, structural, parts etc. without de-energizing the line and with live line is called live line maintenance. The activities in live-line maintenance include:

- Repair of conductor of overhead line or overhead bus bars, overhead earthing wire, while circuit is live.

- Inspection from close distance while circuit live.

- Inspection/repairs/replacements of Insulators, with circuit live.

- Live line washing of insulators.

These terms associated with the state of the circuits are: Live: Connected to the voltage source. Dead: Disconnected and earthed. Disconnected: Disconnected, not earthed. Condition dead is safest, but under circumstances live line maintenance is essential. Person working in the vicinity of a live conductor is subjected to electric field stress. If the person is insulated earth, he will be charged by the alternating electric field. The charging will depend upon the position of the person in the field and the field strength. If the person is touching the grounded part, current will flow through his body to the earth [3].

Live-line tools were first accepted for work on lines up to 34 $\mathrm{kV}$, but many linemen were hesitant to perform hotstick operations on this voltage. Because of this fear, many companies restricted live-line maintenance to $22 \mathrm{kV}$ or less. As linemen began to realize that the use of live-line tools always kept them at a safe distance from energized lines, they began to lose their fear of performing this work, and restrictions were gradually relaxed, until by 1930 several companies were permitting live-line operations to be performed on $66-\mathrm{kV}$ lines.

The rest of the paper is organized as follows. II. Experimental Methods of Maintenance III. Safety precautions IV. Future Scoipe V. Conclusion. 


\section{International Journal of Engineering Applied Sciences and Technology, 2019 \\ Vol. 4, Issue 3, ISSN No. 2455-2143, Pages 157-160 \\ Published Online July 2019 in IJEAST (http://www.ijeast.com)}

\section{METHODS OF LIVE LINE MAINTENANCE}

In general, there are three methods of live-line working which help workers avoid the considerable hazards of live line working. In various ways, they all serve to prevent current flowing from the live equipment through the worker. There are two basic Live Line methodologies for High Voltage (HV) work, which in industry terminology are called 'Hot stick' and 'Bare-hand' methods: Using hot-stick methods, direct human contact with live components is avoided. Line workers use tools fastened to insulated fibre glass poles to carry out the work, and always keep themselves at a safe distance from the live components

- Hot stick or Live Line Tool.

- Insulating Gloves or Rubber Gloves.

- Bare hand or Potential.

- Unearthed or De-energised.

\section{A. Hot stick or Live Line Tool :-}

A hot stick is an insulated pole, usually made of fiberglass, used by electric utility workers when engaged on live-line working on energized high-voltage electric power lines, to protect them from electric shock. Depending on the tool attached to the end of the hot stick, it is possible to test for voltage, tighten nuts and bolts, apply tie wires (twisted lengths of ductile wire which fasten the running cable to its supporting insulators), open and close switches, replace fuses, lay insulating sleeves on wires, and perform various other tasks while not exposing the crew to a large risk of electric shock.

Hot sticks are made in different lengths, from simple 3 foot $(1 \mathrm{~m})$ sticks to 30 foot $(9 \mathrm{~m})$ telescoping models. Because the fiberglass provides electrical insulation, the hot stick allows utility workers to perform operations on power lines safely without de-energizing them or while the state of the power line is not yet known.

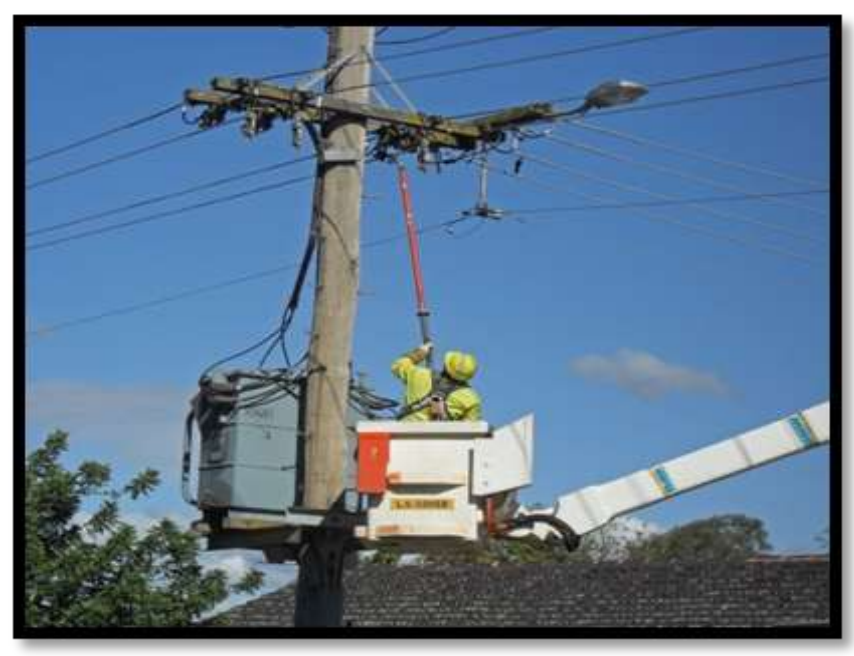

Fig.-1 Hot Stick

This is essential because certain operations (such as opening or closing combination fuse/switches) must occasionally be performed on an energized line. Additionally, after a fault occurs, the exact state of a line may not be certain; in this case, for reasons of crew safety, the utility workers must treat the line as though it were energized until it can be proven that it is not and safety ground cables can be applied to the line (so that the line is guaranteed to remain grounded/earthed while maintenance is performed upon it). If power tools are fitted to the end of the hot stick, they are usually powered hydraulically rather than electrically because, like the fiberglass of the hot stick, the hydraulic fluid is also a good insulator. The hydraulic power is commonly supplied from the bucket truck (cherry picker or aerial work platform) supporting the workers.

In this method the lineman will be at ground potential, working with Hot Sticks (tools) keeping safe clearance from the line.

Table 1. Osha Standards For Safe Working

\begin{tabular}{|c|c|c|}
\hline $\begin{array}{l}\text { Voltage range phase to phase in } \\
\text { KV }\end{array}$ & Meters & FEETS \\
\hline $46.1-72.5$ & 0.91 & 3 \\
\hline $72.6-121$ & 1.02 & 3.4 \\
\hline $138-145$ & 1.07 & 3.6 \\
\hline $161-169$ & 1.12 & 3.8 \\
\hline $230-242$ & 1.52 & 5 \\
\hline $345-362$ & 2.13 & 7 \\
\hline $500-552$ & 3.35 & 11 \\
\hline
\end{tabular}




\section{International Journal of Engineering Applied Sciences and Technology, 2019 Vol. 4, Issue 3, ISSN No. 2455-2143, Pages 157-160 \\ Published Online July 2019 in IJEAST (http://www.ijeast.com)}

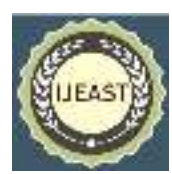

\section{B. Insulating Glove or Rubber Glove Working:-}

Gloves protect the worker from exposure to the live part being worked upon sometimes referred to as the 1st point of contact; the point where current would enter the body should an inadvertent contact be made. Covers of insulating material such as blankets and linehose are employed in rubber glove working to protect the worker from exposure to a part at a different potential sometimes referred to as the 2 nd point of contact; the point where current would leave the body should an inadvertent contact be made. Most utilities require work to be performed from an insulating platform to provide isolation from earth/ground potential hence the term "insulate and isolate"

\section{Bare hand or Potential.}

Live-line work performed by placing the worker at the same potential as the conductor. Here the lineman will be working at line potential keeping safe clearance from ground. For this conductive suits made of $25 \%$ microscopic stainless steel and 75\% nomex will be provided. In 1937, Michel Faraday proved that electricity between two points at the same potential is same. If a Lineman can be shielded in a Faraday Cage, and the cage is bonded to an energized conductor, he may work on the conductor and associated hardware without shock or discomfort.

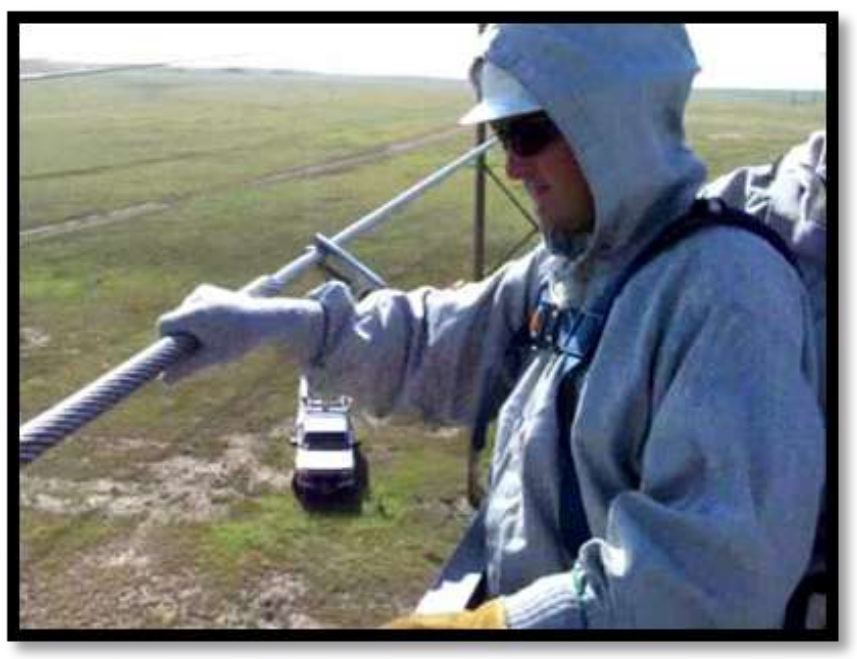

Fig-2 Bare Hand.

\section{SAFETY PRECAUTIONS TAKEN DURING LIVE LINE WORKING}

A golden rule for hot line operation is "nothing is too safe when a life is at stake". Records prove that hot line work on high voltage lines is actually safer than maintenance work on
"Cold" lines which could possibly become energized while the line is being worked. Linemen working with hot sticks are always conscious of the danger involved, and being aware of this danger they work more cautiously and keep a safe distance.

- While working it should be kept in mind that the person working invariably keeps a certain distance from the earth point. In addition to this he should also keep a certain safe distance from the other phases of the lines.

- Use freely safety equipment like cross-arm guards, hand gloves, etc.

- Never use a tool which is not tested and which is not familiar, never use a damp tool.

- Do not exceed the manufacturer's ratings in the use of hot line tools. Linemen must know the approximate weight of a conductor span and the line tensions which they are dealing with. When in doubt use a longer tool or two identical tools.

- Check each tool regularly for indicating that the tool may have been overstressed.

- When not in use, tools should be kept in the tool container and not on the ground.

- All the hotline tools shall be inspected manually and electrical strength test shall be carried out as per design at site.

- All the insulators in the string must be healthy except one or two depending on voltage class.

- Altitude correction factor should be applied in the above electrical clearances.

- Distance from inadvertent movement shall be considered depending on the work procedure and expertise of the lineman.

\section{FUTURE SCOPE}

As per energy experts future work would be online monitoring data, intelligent maintenance using expert systems, reliability analysis and accurate evaluation system. There is need in development of high voltage intelligent equipment's and there residual life estimation and life cycle management system.

- Renovation and Modernization of Generation Sector:-

- Development of National Grid.

- Strengthened role of Renewable in the sector.

- Implementation of modern techniques for electric power conservation (DSM). 
International Journal of Engineering Applied Sciences and Technology, 2019

Vol. 4, Issue 3, ISSN No. 2455-2143, Pages 157-160

Published Online July 2019 in IJEAST (http://www.ijeast.com)

- Introducing Cogeneration Systems.

- Institution of energy audit.

- Adoption of innovative business models.

\section{CONCLUSION}

This study on review of various methods on Transmission line Maintenance and Line monitoring deployed in India by the government utilities and many private parties. Efforts made to highlight the present maintenance techniques and advanced development of maintenance technology based on predictive maintenance \& monitoring of line for future perspective. Paper also shows factors affecting on maintenance techniques with the advanced development technology, research and development since its inception.

\section{Benefits of maintenance technology:-}

- Maintenance Technology with Smart Grid (SG) technology gives features such as maintaining stability of the system, increase in transmission capacity, improving supply quality, improvement in overall performance etc.

- Remodelling the energy scenario of the global market.

- It also improves other performances such as advanced communication, protocol, advanced management and architecture with fast data exchange.

-Environmental Benefits: - The reduction of losses by an increased availability leads to savings in generation and lower emissions of polluting gases in the atmosphere. Also, live-line working procedures and methods are specially designed to address environmental issues, such as the installation of bird flight diverters and the replacement of insulators, spacers and other accessories that generate noise.

- This technology has a quality to improve performance of other technologies such as Flexible AC Transmission System (FACTS) and Wide Area Monitoring (WAM) in urban \& rural area.

\section{REFERENCE}

[1] Wikipedia, the free encyclopaedia.

[2] Planning Commission, Government Of India, Report.

[3] Fengyu Zhou and Yibin Li, et al. (2008). Research on autonomous negotiation action planning for $110 \mathrm{kv}$ power transmission line inspection robot, pp. 74557459, Chongqing, China,2008, IEEE, USA.

[4] Silcock, R. Live maintenance of high voltage transmission lines Safety is paramount. Retrived from
http://www02.abb.com/global/gad/gad02077.nsf/lupL ongContent/5975E9472CDC9 C1256EFA0048910.

[5] Gokturk Poyrazoglu, "Scheduling Maintenance for Reliable Transmission Systems”, IEEE, pp. 1-5, April 2016.

[6] 2016 International Conference on Global Trends in Signal Processing, Information Computing and Communication"EHVAC Transmission Lines Maintenance Techniques in Indian Perspective - A Review".978-1-5090-0467-6/16/\$31.00 @2016 IEEE

[7] New Techniques and Approaches for Live Wire Maintenance of Transmission Lines, IJRASET, Volume 3 Issue VI, June 2015, ISSN: 2321-9653. 